\title{
Male Hypogonadism Causes Obesity Associated with Impairment of Hepatic Gluconeogenesis in Mice
}

\author{
Akira Aoki ${ }^{a}$ Kohei Fujitani, ${ }^{a}$ Kohei Takagi, ${ }^{a}$ Tomoki Kimura, ${ }^{b}$ Hisamitsu Nagase, ${ }^{a}$ and \\ Tsuyoshi Nakanishi*,a \\ ${ }^{a}$ Laboratory of Hygienic Chemistry and Molecular Toxicology, Gifu Pharmaceutical University; 1-25-4 Daigaku- \\ Nishi, Gifu 501-1196, Japan: and ${ }^{b}$ Laboratory of Toxicology, Faculty of Pharmaceutical Sciences, Setsunan \\ University; 45-1 Nagaotoge-cho, Hirakata, Osaka 573-0101, Japan. \\ Received November 26, 2015; accepted December 24, 2015
}

\begin{abstract}
The steroid hormones synthesized by the male gonads play diverse roles in biological processes. Androgens, the primary hormones produced by the male gonads, are key regulators of fat homeostasis, hence androgen-deprivation therapies often induce obesity. However, the molecular mechanism by which male gonadal dysfunction leads to obesity remains unclear, because results from animal studies regarding fat accumulation in the context of gonadal defects do not reflect clinical findings. Here, we investigated the mechanism underlying the development of obesity in animals with male gonadal dysfunction by analyzing the long-term physiological changes in adult male mice with surgical castration. Nine weeks after surgery, white adipose tissue (WAT) mass was higher in the castrated (Cas) mice than in sham-operated (Sham) mice. In addition, castration induced hyperlipidemia and hyperglycemia. However, genes involved in lipid metabolism, including hormone-sensitive lipase, were unchanged in the adipose tissue of the Cas mice, despite the increase in WAT. In contrast, a hepatic gluconeogenesis gene, glucose-6-phosphatase, was significantly upregulated in the Cas mice than in Sham mice. Our findings suggest that long-term hypogonadism in mice mimics the effects in humans, and a potential molecular basis for the induction of obesity in this model is impairment of hepatic gluconeogenesis.
\end{abstract}

Key words castration; fat accumulation; glucose-6-phosphatase (G6Pase); white adipose tissue (WAT); androgen deprivation; mouse

The rates of obesity have increased rapidly over recent decades worldwide. This prevalence is high concern because obesity is closely associated with the development of insulin resistance, type 2 diabetes, metabolic syndrome, and cardiovascular disease. ${ }^{1,2)}$ Obesity is characterized by the storage of excessive fatty acids in adipose tissue and the expansion of fat mass. The gonad has various physiological functions that modulate fat accumulation and is one of the most important organs for determining fat mass.

The male gonad, the testicle, is a crucial organ that both produces spermatozoa and synthesizes steroid hormones, mainly testosterone and other androgens. Because androgens play a central role in development and sexual differentiation, male gonadal function is critical not only for reproduction but also for the organogenesis of male genitalia and the maintenance of male sexual characteristics. ${ }^{3-6)}$ Male hypogonadism is a known risk factor for several disorders, including reproductive, vascular, and bone defects. ${ }^{7-9)}$ In addition, clinical studies have demonstrated that impaired testicular function is associated with increased risk of obesity. Visceral adiposity is induced by aging-related hypogonadism or orchiectomy in patients with prostate cancer, ${ }^{10-13)}$ suggesting that male gonadal function is essential for regulating fat accumulation. However, how the molecular changes in male hypogonadism lead to obesity is not understood fully.

Surgical castration results in metabolic abnormalities in experimental rodent models. For example, in male rats, castration induces insulin resistance with fasting hyperglycemia or hepatic steatosis. ${ }^{14,15)}$ In male mice, castration increases plasma adiponectin levels and induces glucose uptake into white adipose tissue (WAT). ${ }^{16-18)}$ In terms of fat accumulation in WAT, Floryk et al. ${ }^{19)}$ reported that soon after surgical castration (i.e., within $14 \mathrm{~d}$ ), WAT mass is reduced in male mice, even though androgen-depressive therapies clearly induce obesity in human clinical cases. In contrast to this short-term result, a recent study demonstrated that $71 \mathrm{~d}$ after the surgery, the WAT mass of castrated (Cast) rats was higher than that of sham-operated (Sham) rats. ${ }^{20)}$ Although the cited report ${ }^{20)}$ did not focus on the effect of the castration on obesity but rather on bone health, the long-term effect of castration in mice might be obesity, reflecting the results of clinical studies.

Here, we showed the potential utility of a mouse castration model for reproducing the clinical observations that surgical castration induces fat accumulation in WAT. We also investigated the molecular changes involved in the increase in fat mass associated with the obesity induced by male hypogonadism.

\section{MATERIALS AND METHODS}

Animal Male C57BL/6J mice were purchased from Charles River Laboratories Japan and allocated into two treatment groups: Cast and Sham. Mice were Cast or Sham at 9 weeks old. All operative procedures were performed under isoflurane gas anesthesia. Mice were housed in a room maintained at $23 \pm 2{ }^{\circ} \mathrm{C}$ with $50 \pm 10 \%$ humidity and a $12: 12$-h lightdark cycle (lights on from 8:00 a.m. to 8:00 p.m.) and fed a standard chow diet (CE-2; CLEA, Tokyo, Japan). Food and water were provided ad libitum. All animal care and handling procedures were approved by the Institutional Animal Care 
Table 1. Primer Sequences and PCR Conditions for Real-Time RT-PCR

\begin{tabular}{|c|c|c|c|c|c|c|}
\hline \multirow{2}{*}{$\frac{\text { Genes }}{(\text { Accession No.) }}$} & & \multirow{2}{*}{ Primer sequences $\left(5^{\prime}\right.$ to $\left.3^{\prime}\right)$} & \multicolumn{3}{|c|}{ PCR conditions (40 cycles in all cases) } & \multirow{2}{*}{$\begin{array}{l}\text { PCR product } \\
\text { length (bp) }\end{array}$} \\
\hline & & & Denaturation & Annealing & Elongation & \\
\hline HSL & Forward & TATTCAGGGACAGAGGCAGAG & $94^{\circ} \mathrm{C}$ & $62^{\circ} \mathrm{C}$ & $72^{\circ} \mathrm{C}$ & 156 \\
\hline (NM_010719) & Reverse & CTTGCGTCCACTTAGTTCCAG & $15 \mathrm{~s}$ & $30 \mathrm{~s}$ & $30 \mathrm{~s}$ & \\
\hline LPL & Forward & TCCAGAGTTTGACCGCCTTC & $94^{\circ} \mathrm{C}$ & $62^{\circ} \mathrm{C}$ & $72^{\circ} \mathrm{C}$ & 113 \\
\hline (NM_008509) & Reverse & GTCCTCAGCTGTGTCTTCAG & $15 \mathrm{~s}$ & $30 \mathrm{~s}$ & $30 \mathrm{~s}$ & \\
\hline FAS & Forward & GGCTGCTGTTGGAAGTCAG & $94^{\circ} \mathrm{C}$ & $62^{\circ} \mathrm{C}$ & $72^{\circ} \mathrm{C}$ & 160 \\
\hline (NM_007988) & Reverse & ACCATGCTGTAGCCCAGAAG & $15 \mathrm{~s}$ & $30 \mathrm{~s}$ & $30 \mathrm{~s}$ & \\
\hline Scd1 1 & Forward & ATCATACTGGTTCCCTCCTGC & $94^{\circ} \mathrm{C}$ & $62^{\circ} \mathrm{C}$ & $72^{\circ} \mathrm{C}$ & 126 \\
\hline (NM_009127) & Reverse & CCGTGCCTTGTAAGTTCTGTG & $15 \mathrm{~s}$ & $30 \mathrm{~s}$ & $30 \mathrm{~s}$ & \\
\hline G6Pase & Forward & GACTGGTTCAACCTCGTCTTC & $94^{\circ} \mathrm{C}$ & $62^{\circ} \mathrm{C}$ & $72^{\circ} \mathrm{C}$ & 181 \\
\hline (NM_008061) & Reverse & CATAGTATACACCTGCTGCGC & $15 \mathrm{~s}$ & $30 \mathrm{~s}$ & $30 \mathrm{~s}$ & \\
\hline PEPCK & Forward & GTCGAATGTGTGGGCGATG & $94^{\circ} \mathrm{C}$ & $62^{\circ} \mathrm{C}$ & $72^{\circ} \mathrm{C}$ & 118 \\
\hline (NM_011044) & Reverse & TTGTCTTCACTGAGGTGCCAG & $15 \mathrm{~s}$ & $30 \mathrm{~s}$ & $30 \mathrm{~s}$ & \\
\hline$\beta$-Actin & Forward & CCCTGAACCCTAAGGCCAACCGTG & $94^{\circ} \mathrm{C}$ & $62^{\circ} \mathrm{C}$ & $72^{\circ} \mathrm{C}$ & 125 \\
\hline (NM_001101) & Reverse & GCCTGTGGTACGACCAGAGGCATAC & $15 \mathrm{~s}$ & $30 \mathrm{~s}$ & $30 \mathrm{~s}$ & \\
\hline
\end{tabular}

Body weight

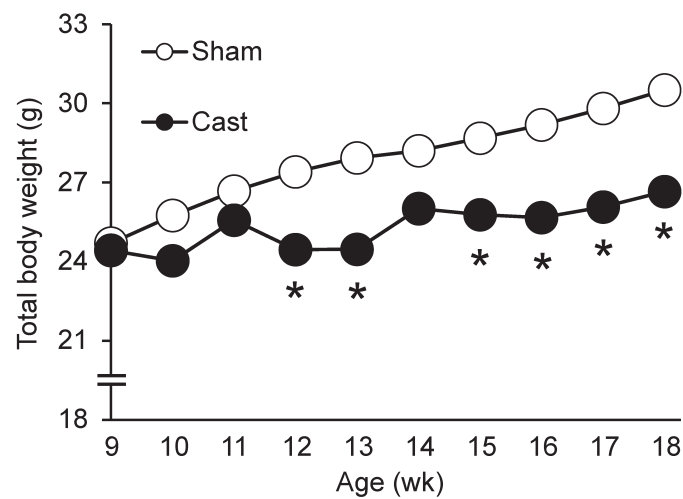

Food intake

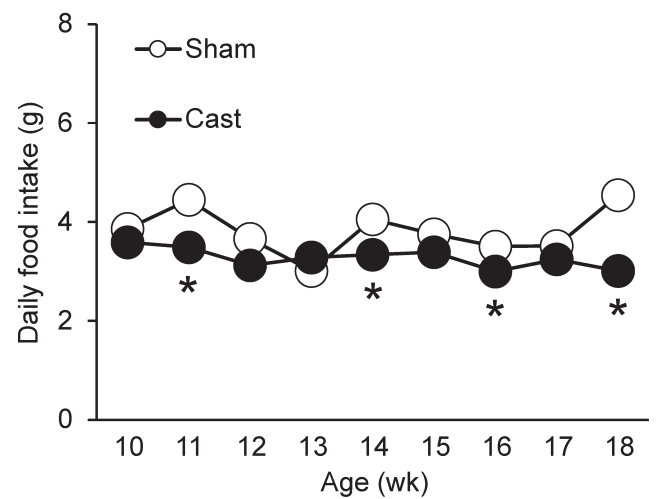

Fig. 1. Effect of Surgical Castration on Total Body Weight and Food Intake in Mice

Male C57BL6/ J mice were castrated (Cast) or sham-operated (Sham) at 9 weeks old and fed a standard chow diet. Total body weight change and food intake were monitored every week throughout the experiment. Results are expressed as the mean $(n=12-14) . * p<0.05$, compared with Sham mice.

and Use Committee of Gifu Pharmaceutical University. All efforts were made to minimize both the number of animals used and the pain and distress they experienced.

Serum Biochemical Test The mice were fasted overnight and euthanized for blood collection. Concentrations of serum triglycerides, nonesterified fatty acids (NEFA), and glucose were quantified individually by using Triglyceride E, NEFA C, and Glucose C II test kits (Wako Pure Chemical Industries, Ltd., Osaka, Japan). ${ }^{21)}$

Isolation of Total RNA, Synthesis of cDNA, and Reverse Transcription-Polymerase Chain Reaction (RT-PCR) Assay Total RNA from liver and WAT was extracted by using TRIzol reagent (Invitrogen, Carlsbad, CA, U.S.A.) and reverse transcribed by using the ImProm-II reagent (Promega, Madison, WI, U.S.A.) with oligo-(dT) as a primer. For the quantitative RT-PCR assay, aliquots of diluted reversetranscription products were amplified by using LightCycler (Roche Diagnostics, Mannheim, Germany) in a reaction mixture containing QuantiTect SYBR Green PCR reagent (Qiagen, Valencia, CA, U.S.A.) and each primer. After preincubation of the reaction mixtures at $95^{\circ} \mathrm{C}$ for $15 \mathrm{~min}$, real-time PCR amplification was performed by using the conditions and primer pairs shown in Table 1. The amount of mRNA of each gene was expressed relative to the amount of mRNA of the housekeeping gene $\beta$-actin.

Statistical Analysis All results are expressed as the mean \pm 1 standard deviation (S.D.) of 2 or 3 independent experiments. Statistical significance was determined by using the Student's $t$-test. All results were performed with SPSS $15.0 \mathrm{~J}$ software (IBM, Chicago, IL, U.S.A.). A $p$ value of $<0.05$ was taken to indicate statistical significance.

\section{RESULTS}

Body Weight, Food Intake, and Tissue Weight To determine whether surgical castration leads to fat accumulation in WAT and other physiological changes in the long term, we analyzed the food intake, total body and organ weights of male mice after castration at 9 weeks of age. Total body weight was significantly lower in Cast mice than in Sham mice at 12, 13, $15,16,17$, and 18 weeks old $(p<0.05)$. Food intake was also significantly lower in the castration group than in the Sham group at 11, 14, 16, and 18 weeks old ( $p<0.05$; Fig. 1).

We then assessed liver weight and WAT weight in mice euthanized at 18 weeks of age. There was no difference in the ratio of liver weight to body weight between Cast mice 
A

White adipose tissue

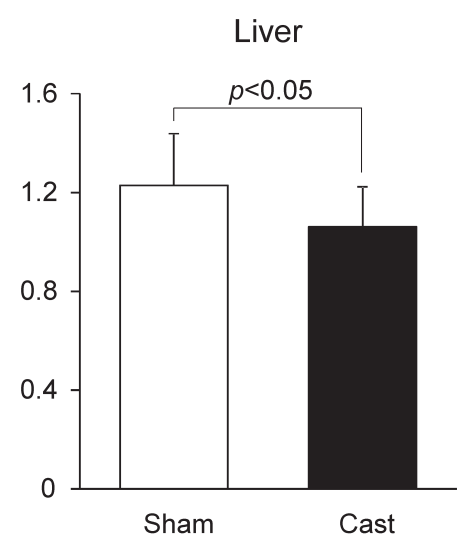

B

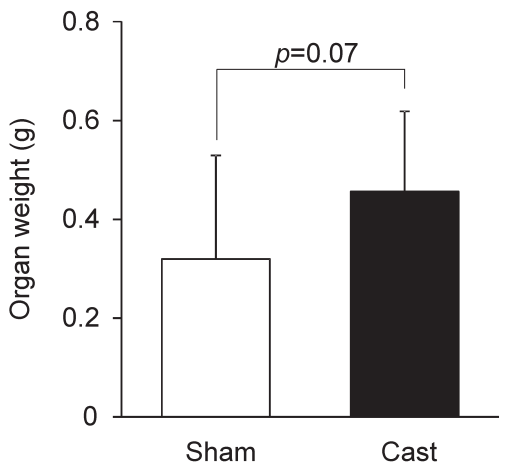

White adipose tissue

Liver
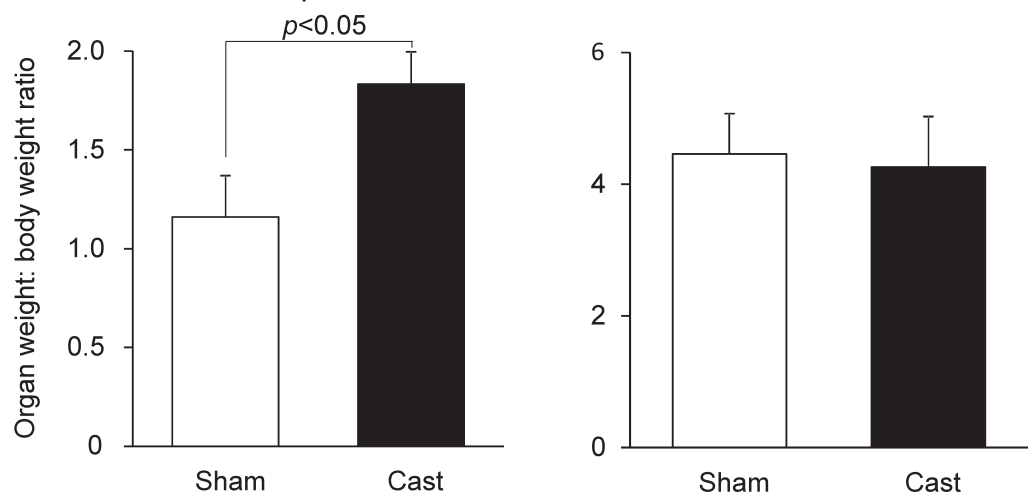

Fig. 2. An Increase in White Adipose Tissue and Liver Weight of Castrated Mice

Male C57BL6/ J mice were castrated (Cast) or sham-operated (Sham) at 9 weeks old and fed a standard chow diet. At 18 weeks of age, the mice were fasted overnight, then euthanized for removal of epididymal white adipose tissue and liver. (A) Weight of white adipose tissue and liver. (B) The ratio of each organ weight to total body weight. Results are expressed as the mean \pm 1 S.D. $(n=12-14)$.

Triglycerides

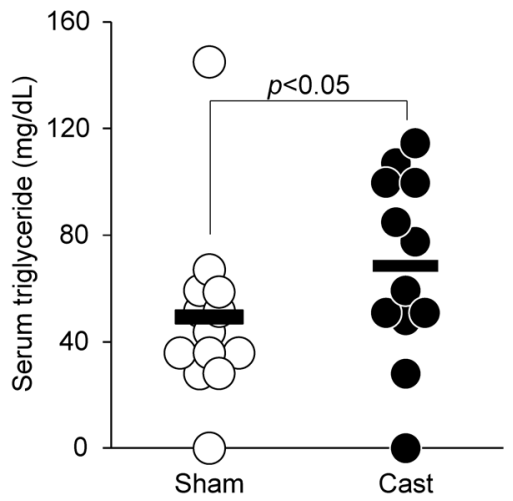

NEFA

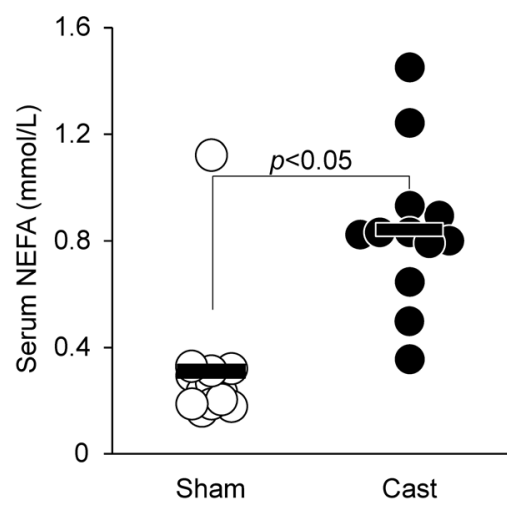

Glucose

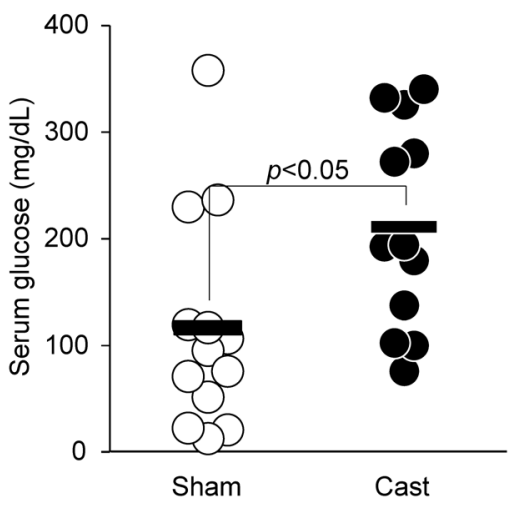

Fig. 3. Hyperlipidemia and Hyperglycemia Induced by the Castration

Male C57BL6/ J mice were castrated (Cast) or sham-operated (Sham) at 9 weeks old and fed a standard chow diet. At 18 weeks of age, the mice were fasted overnight and euthanized for blood collection. Serum triglycerides, nonesterified fatty acids (NEFA), and glucose concentrations were analyzed using biochemical test kits (as described in Materials and Methods). The horizontal bars represent the mean $(n=12-14)$.

and Sham mice (Fig. 2B), but the liver weight was lower in Cast mice than in Sham mice (Fig. 2A). Both the WAT weight $(p=0.07$; Fig. 2A) and the ratio of WAT weight to body weight $(p<0.05$; Fig. 2B) were higher in Cast mice than in Sham mice. These results suggest that the absence of male gonadal function over a relatively long time results in an increase in WAT mass, despite a reduction of total body weight gain.

Serum Biochemical Markers and Adipocyte and He- patocyte Gene Expression To characterize the castrationinduced obesity in male mice, we examined the levels of typical serum biochemical markers (triglycerides, NEFA, and glucose) in Cast mice during fasting. Consistent with the results regarding WAT mass (Fig. 2), serum triglycerides and NEFA levels in Cast mice were significantly higher than those in Sham mice $(p<0.05)$. Furthermore, surgical castration resulted in a significant increase in levels of serum glucose 
A

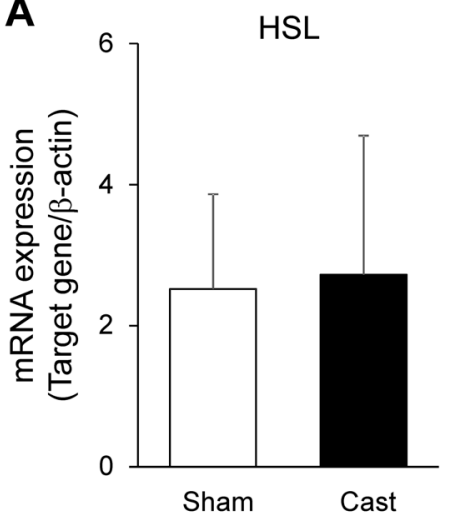

B

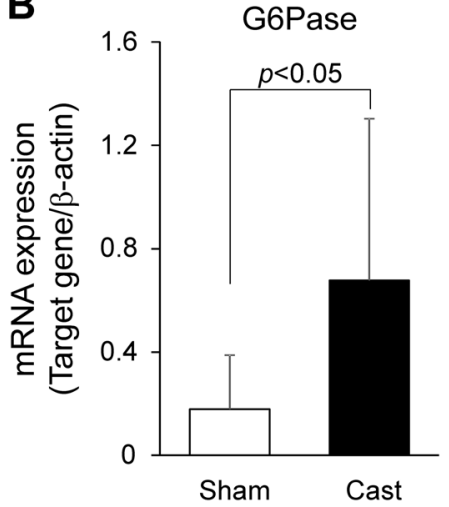

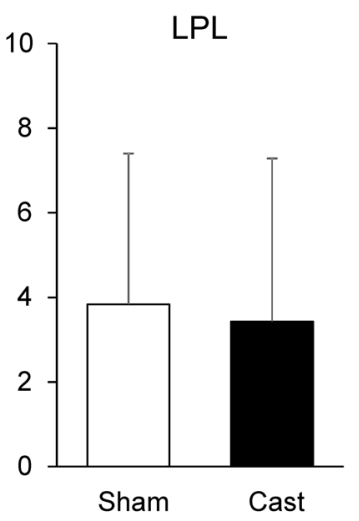

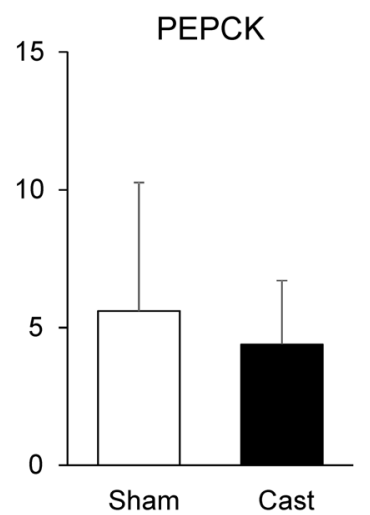

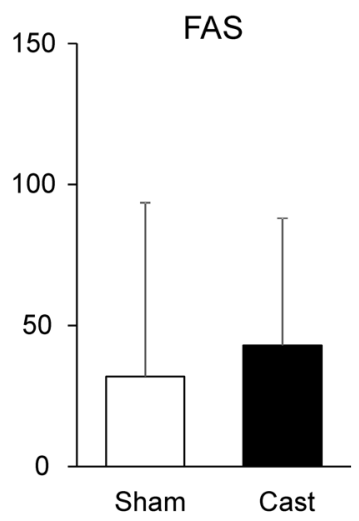

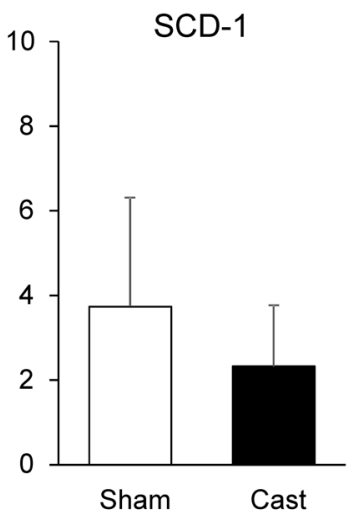

Fig. 4. Castration Induces Hepatic Gluconeogenesis and Decreases Androgen Activity

C

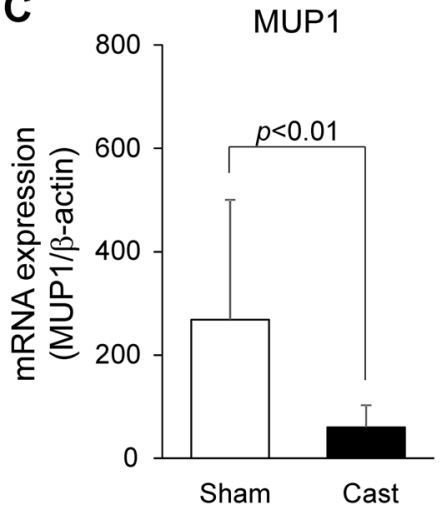

Male C57BL6/ J mice were castrated (Cast) or sham-operated (Sham) at 9 weeks old and fed a standard chow diet. At 18 weeks of age, the mice were fasted overnight, and euthanized for isolation of total RNA from liver and WAT. mRNA expression of genes involved in (A) adipocyte lipid metabolism, including HSL, LPL, FAS, and SCD-1; (B) hepatic gluconeogenesis, including G6Pase and PEPCK; and (C) an androgen-responsive gene, MUP1, were analyzed by real-time RT-PCR. Results are expressed as the mean \pm 1 S.D. $(n=12-14)$.

\section{$(p<0.05$; Fig. 3).}

To examine the potential molecular basis of obesity induced by male gonadal defects, we analyzed the mRNA expression of genes involved in adipocyte lipid metabolism: hormonesensitive lipase (HSL), lipoprotein lipase (LPL), fatty acid synthetase (FAS), and stearoyl-CoA desaturase (SCD-1) (Fig. 4A). Unexpectedly, castration did not change the expression of any of these genes in WAT. In addition, we analyzed the mRNA expression of most important genes involved in hepatic gluconeogenesis: glucose-6-phosphatase (G6Pase) and phosphoenolpyruvate carboxykinase (PEPCK). In contrast to adipogenetic genes, G6Pase, but not PEPCK, was significantly higher in Cast mice than that in Sham mice $(p<0.05$; Fig. 4B). These results suggest that male gonadal dysfunction may induce obesity with hyperlipidemia and hyperglycemia by affecting hepatic gluconeogenesis. Therefore, we analyzed the expression of major urinary protein 1 (MUP1), which is a typical androgen-responsive gene in mouse liver, ${ }^{22,23)}$ to confirm that the surgical castration had attenuated androgen activity in the liver. The level of MUP1 in the livers of Cast mice was significantly decreased compared with that in Sham mice ( $p<0.01$; Fig. 4 C), suggesting that surgical castration did sufficiently attenuate androgen activity.

\section{DISCUSSION}

Clinical observations indicate that male gonadal dysfunc- tion induces obesity, because men who have undergone castration or who have hypogonadism have excess fat accumulation in WAT. ${ }^{10-13)}$ However, using an experimental animal model, no study has used an experimental animal model to investigate how male gonadal dysfunction induces increased fat accumulation in WAT and obesity. In our current study, we analyzed the long-term effect of castration on WAT mass in a mouse model. Nine weeks after surgical castration, WAT mass was significantly increased in Cast mice compared with Sham mice (Fig. 2). In addition, the surgical castration resulted in hyperlipidemia and increased levels of serum triglycerides and NEFA (Fig. 3). Consistent with these results, clinical studies have demonstrated that obese men who have undergone androgen-deprivation therapy have high levels of both serum triglycerides and NEFA, as well as excessive WAT mass. ${ }^{1024)}$ Our data demonstrate that this mouse model may be relevant for understanding the molecular mechanisms of obesity caused by male gonadal defects, and a period as short as 9 weeks after castration is adequate to reproduce the effect of male gonadal dysfunction on obesity that is seen clinically.

In another animal model of obesity, feeding mice a highfat diet also induced fat accumulation in WAT and increases in serum levels of NEFA; however, the serum triglycerides were decreased. ${ }^{25)}$ These data suggest that a high-fat diet and surgical castration lead to obesity through different molecular mechanisms.

In our current study, Cast mice had lower total body weight 
as compared with Sham mice (Fig. 1). Several studies have showed that surgical castration results in loss of bone and muscle mass. ${ }^{26-28)}$ Consistent with our results, Koncarevic et $a l .{ }^{20)}$ showed that at $71 \mathrm{~d}$ after surgical castration in rats, total body weight had declined due to loss of bone and muscle mass, whereas the WAT mass was higher than that in Sham mice. In addition, in our current study, Cast mice had decreased liver weight (Fig. 2). In general, liver mass declines with age, and this effect has been attributed to a decrease in the number of hepatic cells and a reduction of blood flow. ${ }^{29,30)}$ Taken together, these findings suggest that the loss of total body weight in the current model of surgical castration probably resulted from loss of bone, muscle, and liver mass, similar to the process when gonadal function declines with age.

Results obtained in male androgen-receptor knockout (ARKO) mice have led to the conclusion that androgens play an important role in male metabolism by affecting the energy balance and adiposity. Among transcripts involved in adipocyte lipid homeostasis, the HSL level in the WAT of ARKO mice was sharply downregulated, and the LPL level was significantly decreased compared with the levels in control mice. ${ }^{31,32)}$ However, we found no change in the levels of HSL and LPL between Cast mice and Sham mice (Fig. 4A). Instead, castration in male mice impaired hepatic gluconeogenesis (Fig. 4B). In addition, Cast mice had higher fasting serum glucose levels as compared with Sham mice (Fig. 3), whereas ARKO mice are not hyperglycemic. ${ }^{31)}$ Therefore, to verify the effect of castration on androgen activity, we analyzed the levels of a hepatic androgen-responsive gene, MUP1. ${ }^{22,23)} \mathrm{We}$ found a significant decrease of MUP1 in Cast mice compared with the level in Sham mice (Fig. 4C), confirming the effect of castration on androgen signaling and suggesting that the mechanisms by which castration and ARKO induce obesity are not completely identical. In previous reports, Cast rats displayed hepatic insulin resistance with an increase in fasting serum glucose levels. ${ }^{15)}$ In addition, several studies have suggested that hypogonadism induces abnormal hepatic regulation of glucose homeostasis..$^{10,14,15,24)}$ Hence, unlike in ARKO mice, surgical castration may induce obesity mainly via involvement of hepatic gluconeogenesis rather than adipocyte lipid metabolism. However, more information is needed about the profiles of genes which are highly regulated by androgens as well as HSL in Cast mice.

To investigate the effect of surgical castration in hepatic gluconeogenesis, we analyzed the expression levels of two gluconeogenic genes, G6Pase and PEPCK which are known as rate-limiting enzymes to maintain plasma glucose homeostasis at the beginning and the end of the gluconeogenic cycle, respectively. ${ }^{33)}$ Although there was no change in PEPCK expression, the expression levels of G6Pase in liver of Cast mice was significantly higher than that in Sham mice (Fig. 4B). In a previous in vitro study, overexpression of G6Pase in rat hepatocyte results in an increase of glucose production. ${ }^{34)}$ In addition, rats overexpressing hepatic G6Pase in vivo exhibited several of the abnormalities associated with early stage in type 2 diabetes. ${ }^{35)}$ All of the above findings together suggest that hyperglycemia induced by male gonadal dysfunction may be due to an increase of hepatic G6Pase expression.

In summary, we showed that Cast mice at 9 weeks after surgery are an appropriate model for obesity induced by male gonadal dysfunction. Using this model, we demonstrated that male hypogonadism induces obesity that is associated with impairments in hepatic gluconeogenesis. Male hypogonadism induced excessive fat accumulation in WAT and hyperlipidemia, independent of adipocyte lipid metabolism. Although further investigations are needed to clarify the underlying mechanisms by which castration induces obesity, our current observations suggest that hepatic gluconeogenesis, rather than the absence of androgen activity, is one of the major pathways of obesity caused by male hypogonadism. Future studies with this animal model should provide additional insights into the molecular mechanisms underlying obesity caused by male gonadal dysfunction.

Conflict of Interest The authors declare no conflict of interest.

\section{REFERENCES}

1) Haslam DW, James WP. Obesity. Lancet, 366, 1197-1209 (2005).

2) Hossain P, Kawar B, El Nahas M. Obesity and diabetes in the developing world-A growing challenge. N. Engl. J. Med., 356, 213-215 (2007)

3) Jost A, Price D, Edwards RG. Hormonal factors in the sex differentiation of the mammalian foetus. Philos. Trans. R. Soc. Lond. B Biol. Sci., 259, 119-130 (1970).

4) Liu CF, Bingham N, Parker K, Yao HH. Sex-specific roles of beta-catenin in mouse gonadal development. Hum. Mol. Genet., 18, 405-417 (2009).

5) Murashima A, Miyagawa S, Ogino Y, Nishida-Fukuda H, Araki K, Matsumoto T, Kaneko T, Yoshinaga K, Yamamura K, Kurita T, Kato S, Moon AM, Yamada G. Essential roles of androgen signaling in Wolffian duct stabilization and epididymal cell differentiation. Endocrinology, 152, 1640-1651 (2011).

6) Renfree MB, Fenelon J, Wijiyanti G, Wilson JD, Shaw G. Wolffian duct differentiation by physiological concentrations of androgen delivered systemically. Dev. Biol., 334, 429-436 (2009).

7) Bain J. Testosterone and the aging male: to treat or not to treat? Maturitas, 66, 16-22 (2010).

8) Jansson JO, Ekberg S, Isaksson OG, Eden S. Influence of gonadal steroids on age- and sex-related secretory patterns of growth hormone in the rat. Endocrinology, 114, 1287-1294 (1984).

9) Webb CM, Elkington AG, Kraidly MM, Keenan N, Pennell DJ, Collins P. Effects of oral testosterone treatment on myocardial perfusion and vascular function in men with low plasma testosterone and coronary heart disease. Am. J. Cardiol., 101, 618-624 (2008).

10) Hakimian P, Blute M Jr, Kashanian J, Chan S, Silver D, Shabsigh R. Metabolic and cardiovascular effects of androgen deprivation therapy. BJU Int., 102, 1509-1514 (2008).

11) Shastri BR, Yaturu S. Metabolic complications and increased cardiovascular risks as a result of androgen deprivation therapy in men with prostate cancer. Prostate Cancer, 2011, 391576 (2011).

12) Smith MR, Finkelstein JS, McGovern FJ, Zietman AL, Fallon MA, Schoenfeld DA, Kantoff PW. Changes in body composition during androgen deprivation therapy for prostate cancer. J. Clin. Endocrinol. Metab., 87, 599-603 (2002).

13) Walsh PC, The Medical Research Council Prostate Cancer Working Party Investigators Group. Immediate versus deferred treatment for advanced prostatic cancer: initial results of the Medical Research Council trial. The Medical Research Council Prostate Cancer Working Party Investigators Group. J. Urol., 158, 1623-1624 (1997).

14) Nikolaenko L, Jia Y, Wang C, Diaz-Arjonilla M, Yee JK, French SW, Liu PY, Laurel S, Chong C, Lee K, Lue Y, Lee WN, Swerdloff RS. Testosterone replacement ameliorates nonalcoholic fatty liver disease in castrated male rats. Endocrinology, 155, 417-428 (2014).

15) Xia F, Xu X, Zhai H, Meng Y, Zhang H, Du S, Xu H, Wu H, Lu Y. 
Castration-induced testosterone deficiency increases fasting glucose associated with hepatic and extra-hepatic insulin resistance in adult male rats. Reprod. Biol. Endocrinol., 11, 106 (2013).

16) Inoue T, Zakikhani M, David S, Algire C, Blouin MJ, Pollak M. Effects of castration on insulin levels and glucose tolerance in the mouse differ from those in man. Prostate, 70, 1628-1635 (2010).

17) Nishizawa H, Shimomura I, Kishida K, Maeda N, Kuriyama H, Nagaretani H, Matsuda M, Kondo H, Furuyama N, Kihara S, Nakamura T, Tochino Y, Funahashi T, Matsuzawa Y. Androgens decrease plasma adiponectin, an insulin-sensitizing adipocyte-derived protein. Diabetes, 51, 2734-2741 (2002).

18) Oh YS, Lee TS, Cheon GJ, Jang IS, Jun HS, Park SC. Modulation of insulin sensitivity and caveolin-1 expression by orchidectomy in a nonobese type 2 diabetes animal model. Mol. Med., 17, 4-11 (2011).

19) Floryk D, Kurosaka S, Tanimoto R, Yang G, Goltsov A, Park S, Thompson TC. Castration-induced changes in mouse epididymal white adipose tissue. Mol. Cell. Endocrinol., 345, 58-67 (2011).

20) Koncarevic A, Cornwall-Brady M, Pullen A, Davies M, Sako D, Liu J, Kumar R, Tomkinson K, Baker T, Umiker B, Monnell T, Grinberg AV, Liharska K, Underwood KW, Ucran JA, Howard E, Barberio J, Spaits M, Pearsall S, Seehra J, Lachey J. A soluble activin receptor type IIb prevents the effects of androgen deprivation on body composition and bone health. Endocrinology, 151, 4289-4300 (2010).

21) Wu X, Iguchi T, Hirano J, Fujita I, Ueda H, Itoh N, Tanaka K, Nakanishi T. Upregulation of sodium-dependent vitamin $\mathrm{C}$ transporter 2 expression in adrenals increases norepinephrine production and aggravates hyperlipidemia in mice with streptozotocin-induced diabetes. Biochem. Pharmacol., 74, 1020-1028 (2007).

22) Hastie ND, Held WA, Toole JJ. Multiple genes coding for the androgen-regulated major urinary proteins of the mouse. Cell, 17, 449-457 (1979).

23) Mullany LK, Hanse EA, Romano A, Blomquist $\mathrm{CH}$, Mason JI, Delvoux B, Anttila C, Albrecht JH. Cyclin D1 regulates hepatic estrogen and androgen metabolism. Am. J. Physiol. Gastrointest. Liver Physiol., 298, G884-G895 (2010).

24) Saylor PJ, Smith MR. Metabolic complications of androgen deprivation therapy for prostate cancer. J. Urol., 181, 1998-2006, discus- sion, 2007-2008 (2009).

25) Guo J, Jou W, Gavrilova O, Hall KD. Persistent diet-induced obesity in male $\mathrm{C} 57 \mathrm{BL} / 6$ mice resulting from temporary obesigenic diets. PLoS ONE, 4, e5370 (2009).

26) Axell AM, MacLean HE, Plant DR, Harcourt LJ, Davis JA, Jimenez M, Handelsman DJ, Lynch GS, Zajac JD. Continuous testosterone administration prevents skeletal muscle atrophy and enhances resistance to fatigue in orchidectomized male mice. Am. J. Physiol. Endocrinol. Metab., 291, E506-E516 (2006).

27) Christoffersen B, Raun K, Svendsen O, Fledelius C, Golozoubova $\mathrm{V}$. Evalution of the castrated male Sprague-Dawley rat as a model of the metabolic syndrome and type 2 diabetes. Int. J. Obes. (Lond.), 30, 1288-1297 (2006).

28) Vanderschueren D, Vandenput L, Boonen S, Lindberg MK, Bouillon R, Ohlsson C. Androgens and bone. Endocr. Rev., 25, 389-425 (2004).

29) Sato T, Cespedes RF, Goyenaga PH, Tauchi H. Age changes in the livers of Costa Ricans. Mech. Ageing Dev., 11, 171-178 (1979).

30) Tauchi H. On the fundamental morphology of the senile changes. Nagoya J. Med. Sci., 24, 97-132 (1961).

31) Fan W, Yanase T, Nomura M, Okabe T, Goto K, Sato T, Kawano H, Kato S, Nawata H. Androgen receptor null male mice develop lateonset obesity caused by decreased energy expenditure and lipolytic activity but show normal insulin sensitivity with high adiponectin secretion. Diabetes, 54, 1000-1008 (2005).

32) Yanase T, Fan W, Kyoya K, Min L, Takayanagi R, Kato S, Nawata $\mathrm{H}$. Androgens and metabolic syndrome: lessons from androgen receptor knock out (ARKO) mice. J. Steroid Biochem. Mol. Biol., 109, 254-257 (2008)

33) Yabaluri N, Bashyam MD. Hormonal regulation of gluconeogenic gene transcription in the liver. J. Biosci., 35, 473-484 (2010).

34) Seoane J, Trinh K, O'Doherty RM, Gomez-Foix AM, Lange AJ, Newgard CB, Guinovart JJ. Metabolic impact of adenovirus-mediated overexpression of the glucose-6-phosphatase catalytic subunit in hepatocytes. J. Biol. Chem., 272, 26972-26977 (1997).

35) Trinh KY, O'Doherty RM, Anderson P, Lange AJ, Newgard CB. Perturbation of fuel homeostasis caused by overexpression of the glucose-6-phosphatase catalytic subunit in liver of normal rats. $J$. Biol. Chem., 273, 31615-31620 (1998). 